\title{
Research on the Influence Model of Psychological Distance on the Identification of Social Entrepreneurship
}

\author{
Hao Zhang ${ }^{1 *} \quad$ Xiaobao Peng ${ }^{2}$ \\ 1.School of Public Affairs, University of Science and Technology of China 1129 Huizhou Avenue, Baohe \\ District, Hefei, Anhui, China \\ 2.School of Public Affairs, University of Science and Technology of China No. 96, Jinzhai Road, Baohe District, \\ Hefei, Anhui, China
}

\begin{abstract}
Based on the theory of Construal Level, this paper explains the logical relationship between time distance, spatial distance, social distance, probability distance and social entrepreneurship opportunity identification based on the theory of mental distance and social entrepreneurship opportunity identification. The corresponding relationship hypothesis is put forward, and the psychological distance impact model for social entrepreneurship opportunity identification is constructed accordingly. Finally, the paper points out the limitations of research and the direction of future research.
\end{abstract}

Keywords: Construal level theory; psychological distance; social entrepreneurship opportunity identification

DOI: $10.7176 /$ RHSS/9-8-06

Publication date: April $30^{\text {th }} 2019$

\section{Introduction}

Social entrepreneurship, as a social innovation model with embedded social goals, is mainly caused by the failure of the government, the market and non-profit organizations to face failure dilemma. At present, with the social and entrepreneurial reform and innovation boom in the world, social entrepreneurship has become a research hotspot in the field of entrepreneurship (Weerawardena \& Mort, 2006; Stevens et al., 2014; Choi \& Majumdar, 2014). Among them, research on the identification of opportunities for social entrepreneurship is becoming more and more important. Because entrepreneurial opportunity identification is the starting point of entrepreneurship (Baron, 2007). Social entrepreneurship opportunity identification is seen as the ability of entrepreneurs to provide solutions to solve social problems (Yitshaki, Kropp, 2015). The core of entrepreneurial success lies in identifying opportunities that are worth pursuing (Mcmullen \& Shepherd, 2006). So, how to identify social entrepreneurship opportunities, especially for the same opportunity, why some entrepreneurs think it is an opportunity, and some entrepreneurs think it is not an opportunity (Shaver \& Scott, 1992; Shane \& Venkataraman, 2000; Ardichvilia et al., 2003). In this regard, the main reason for this paper through literature research is that entrepreneurs have different cognitive perceptions of social entrepreneurship opportunities. Since the social cognition formed by entrepreneurs is mainly based on past and present experience, the judgments and decisions they make on entrepreneurial opportunities are largely uncertain (Mcmullen \& Shepherd, 2006). Therefore, how to promote entrepreneurs to identify social entrepreneurial opportunities and improve entrepreneurs' judgment and decision-making on social entrepreneurial information has become the key to this paper.

This paper argues that the Construal Level Theory (CLT) in the field of cognitive psychology has an important influence on promoting social entrepreneurs' perception of social entrepreneurship information and improving the level of social entrepreneurship decision-making. Because the theory of construal Level suggests that individuals can achieve social cognitive goals by forming abstract psychological interpretations of distant objects (Trope \& Liberman, 2010), and this theoretical perspective is essential for entrepreneurs to recognize social entrepreneurial activities and identify opportunities for social entrepreneurship. According to the theory of construal Level, psychological distance is a subjective experience of individual existence, and this experience mode divides the external world into four distance dimensions of time, space, society and probability according to the perceptual dimension (Trope \& Liberman, 2010). For the identification of social entrepreneurship opportunities, the essence of identification is the series of judgments and decisions made by entrepreneurs based on actual conditions. The key to successful identification of social entrepreneurial opportunities lies in whether the core of entrepreneurial judgment and decision-making deviates from the trend of development things. But in reality, not all social entrepreneurs can accurately grasp the trend of things development. On the contrary, most judgments and decisions have made mistakes, which ultimately lead to social entrepreneurship failure. As a cognitive tool, psychological distance can not only provide ideas for explaining the reasons for the failure of social entrepreneurs, but also help social entrepreneurs to identify entrepreneurial opportunities. As we all know, the basis for social entrepreneurs to identify opportunities lies in the information of the external world, which includes both the degree of information mastery and the degree of information understanding. The degree of information mastery is the key to entrepreneurs' understanding of information, and the degree of information understanding is the basis that influences the final identification of social entrepreneurship opportunities. According to the research in this paper, 
the mastery of information is only the collection of objective information. The processing and processing of collected information is the key to the degree of entrepreneurs' understanding of information, and it also affects the judgment and decision-making of social entrepreneurs on the development trend of things. Therefore, based on the psychological distance in explaining the role of the individual's cognitive external world, this study focuses on how the psychological distance affects the cognition of social entrepreneurs, which in turn affects the identification of social entrepreneurship opportunities. Based on this, because the academic community's research on social entrepreneurship opportunity identification is still in the stage of theoretical exploration, especially the lack of connection and support with other disciplines, this situation limits the development of social entrepreneurship theory. The research of this paper mainly constructs the psychological distance to social entrepreneurship opportunity identification model from the theoretical level, and hopes to further promote the social entrepreneurship opportunity identification research through the theoretical analysis and relationship hypothesis of psychological distance and social entrepreneurship opportunity identification. Therefore, the main theoretical contribution to the discussion of this paper is to introduce the theory of construal Level in cognitive field into the research of social entrepreneurship opportunity identification, which is of great significance to promote the integration of construal Level theory and social entrepreneurship opportunity identification theory.

\section{Theoretical basis}

Construal Level Theory (CLT) is a new theory in the field of social cognitive psychology. After Liberman and Trope published the research results on time interpretation theory in 1998, the main theory of construal Level theory was verified and developed rapidly, which promoted the extension of construal Level theory from time dimension to other dimensions, and deepened the application of construal Level theory. In essence, the theory of construal Level is an individual systematic analysis framework constructed by the combination of abstract concepts and psychological distances. The core of the theory is to explore how individual psychological distance affects their thoughts and behaviors (Trope, Liberman \& Wakslak, 2007). According to the theory of construal Level, the individual psychological distance determines the degree of abstraction of the psychological representation of the event (Liberman \& Trope, 1998). The individual tends to have a high-level interpretation of the psychological representation of objects and events with far-reaching psychological distances, while the objects with close psychological distances and the psychological characterization of events that tend to be interpreted at low levels (Liberman \& Trope, 1998; Liberman, Sagristano \& Trope, 2002; Liberman \& Trope, 2003). The level of interpretation has high and low points, which represent the psychological representation of high-level interpretation and low-level interpretation, respectively. High-level interpretation has abstract, simplistic, and target-related characteristics. Low-level interpretation is specific, complicated, and object-independent. (Liberman \& Trope, 2003; Trope, Liberman \& Wakslak, 2007). Different levels of interpretation indicate that individuals are aware of and understand the different psychology of things. In addition, psychological distance also affects the subjective value that individuals give to explain events. According to the theory of construal Level, high-level interpretation emphasizes desirability, while low-level interpretation emphasizes feasibility (Liberman \& Trope, 1998). Among them, desirability is about the valence of the final state of behavior ("why" to do this), and feasibility is the difficulty of achieving the final state ("how to" do this) (Liberman \& Trope, 1998; Trope, Liberman \& Wakslak, 2007). Psychological distance belongs to one of the core concepts of the theory of construal Level. It refers to a subjective experience in which an individual is close to or away from the self, at this time and here. According to the theory of construal Level, the individual's psychological representation of things is self-centered, the reference point is the self, the time and the place, and there is a psychological distance when the individual perceives things away from and close to the representative body Trope \& Liberman, 2010). The psychological distance has four dimensions, including temporal distance, social distance, and probability distance. Specifically, the time distance refers to an individual's subjective experience of how long things happen. Liberman and Trope (1998) found that time distance affects people's subjective psychology. For long-term events, people's explanations are more abstract and contain important features of event meaning; for recent events, people's explanations are more specific, and Contains event peripherals, incidental features. People use high-level explanations for longterm events, focus on "Why", which represents the choice of event target value, and use low-level explanations for recent events, focusing on "How", which represents the choice of means and methods for achieving the ultimate goal. Spatial distance refers to the subjective experience formed by the individual's spatial proximity to the event. Compared with the time distance dimension, the research results of spatial distance are less. Fujita et al. (2006) studied spatial distances and allowed New York University students to participate in two experiments with far and near spatial distances. The results show that the spatial distance of events occurs when participants tend to regard them as purposes rather than Means; compared with recent events, participants are more inclined to use abstract language to recall events with distant spatial distances, which proves that events with distant spatial distance are related to high-level interpretation, and events with close spatial distance are related to low-level interpretation. Social distance refers to the subjective experience formed by individuals in relation to people (for example: self and others, friends and strangers, within groups and outside the group). From the research point of view, there are 
two main forms of social distance: one is the individual's experience of self-other relationship. Trope et al. (2007) pointed out that if the other people are less similar to themselves, the social relationship between them is alienated; if they are themselves, the psychological distance is zero, indicating that the more similar the others are to the individual, the closer the psychological distance is, the more Not similar, psychological distance is far. The second is the individual's experience of power. Trope et al. (2007) suggest that the promotion of power increases the psychological distance between individuals and others. Smith and Trope (2006) suggest that in terms of low power, high sense of power makes individuals feel that they are farther apart from others, that individual cognition is linked to abstract thinking, focusing on the main and core content. The probability distance is the subjective experience formed by the individual's probability of occurrence of the event. Probability distance refers to the distance independent of time, space and social distance, that is, an event is possible but uncertain (Wakslak et al., 2006). Studies have shown that for less likely outcomes than possible, the psychological distance is far away (Trope et al., 2007), individuals lack other information to understand and the thinking level tends to a higher level of interpretation, and vice versa. Make the psychological distance closer. In short, although there are specific differences in the four dimensions of the distance between the hearts, they have similar mechanisms, close connections, and mutual influence.

\section{Social entrepreneurship opportunity identification model construction}

\subsection{Relationship between time distance and social entrepreneurship opportunity identification}

Social entrepreneurship opportunities, as opportunities with embedded social goals, are characterized not only by economic profits but also by social values (Austin, 2006; Yitshaki \& Kropp, 2015). While all entrepreneurial behaviors begin with attractive opportunities, an attractive opportunity for social entrepreneurship is sufficient and has the potential to generate positive social impact (Guclu et al., 2002). In this regard, how do social entrepreneurs identify opportunities? Social entrepreneurship opportunity identification is a process, and the starting point of its identification behavior is to obtain external information related to social entrepreneurship opportunities, including policy, market, technology, risk and other aspects. It can be said that this is a process of searching and integrating collection information, focusing on the amount of information and paving the way for entrepreneurs to identify the next step. The second step in identifying behavior is to abstract and perceive the acquired information. The purpose is to grasp the essence and core content related to social entrepreneurship opportunities, but the cognition of social entrepreneurial information and the cognitive tools and identification of entrepreneurs. Knowledge is closely related. In this regard, the academic community has carried out a lot of research from the perspective of social cognition, and recognizes that the cognition of entrepreneurs is related to the opportunity identification result. For example, Baron (2006) proposes that entrepreneurs use cognitive frameworks to acquire new products and services, and these ideas are the basis for entrepreneurial success. Baron (2007) proposed that cognitive patterns are the basis of opportunity identification, and entrepreneurs' knowledge of information affects entrepreneurial cognition. Dacin et al. (2011) proposed that the knowledge and information processing capabilities of social entrepreneurs are related to the decision-making of opportunities. From this perspective, the cognition of social entrepreneurs affects their understanding of entrepreneurial information, which in turn affects the judgment and decision-making of social entrepreneurship opportunities. Time distance, as the cognitive dimension of an individual, highlights the influence of the time and time of the event or behavior on the individual's psychology and behavior. According to the theory of construal Level, individuals initiate high-level interpretations of events occurring in the future, paying attention to the essential, general and non-contextual characteristics of event information, initiating low-level interpretations of events occurring in the near future, focusing on event specifics. Background characteristics (Liberman \& Trope, 2003). In combination with the identification of social entrepreneurship opportunities, social entrepreneurs have a process of psychological representation of the information they have already grasped, but due to the different attention to the opportunity identification results, social entrepreneurs may start different levels of interpretation. Thereby forming different entrepreneurial cognitions. Specifically, if social entrepreneurs are based on entrepreneurial behaviors that occur in the future, they will have less information and more specific information about remote targets, thus promoting their higher level of abstraction. It is related to the essence and core of social entrepreneurial information, and if social entrepreneurs are based on entrepreneurial behaviors that occur in the near future, they are enriched by the information they have and the specific information about the near-end goals is clear, thus promoting their mastery. The information obtained is less abstract, paying attention to specific and detailed content, and is susceptible to a large amount of information interference during the decision-making, and even misleading of the wrong information. In addition, research indicates that individuals' attitudes toward the future are more optimistic and confident than in the near future (Liberman \& Trope, 1998). If social entrepreneurs are based on long-term future business plans, they may maintain a positive attitude toward the prediction and judgment of the future, which will help social entrepreneurs take action to identify opportunities. Therefore, this paper proposes the following assumption:

H1: Time distance has a significant positive impact on the identification of social entrepreneurship opportunities. 


\subsection{Relationship between spatial distance and social entrepreneurship opportunity identification}

Spatial distance is an individual cognitive dimension, and the distance based on spatial location affects individual psychology and behavior. At present, although the academic research on spatial distance is less, it has a meaningful meaning according to the psychological distance dimension. If the incident or the spatial distance of the behavior is far away, the individual initiates a high level of interpretation, paying attention to the nature or core content of the event or behavior. The spatial distance of the occurrence of the leave or behavior is close, and the individual initiates a low level of interpretation, focusing on the specific and detailed content of the event or behavior (Trope, Liberman \& Wakslak, 2007). In combination with the identification of social entrepreneurship opportunities, entrepreneurs' choice of social entrepreneurship regions will affect their perception of social entrepreneurship opportunities. Chen et al. (2018) pointed out that entrepreneurs may have different understandings and perceptions of corresponding economic and social factors because of the location choice of entrepreneurial location, including legal system, infrastructure, customers, regional culture and talents. That is to say, from the perspective of the entrepreneur's perception, if the position of the social enterprise is far from the entrepreneur itself, then the social entrepreneur may psychologically represent the relevant cognitive information with a higher abstraction, and if the social enterprise The position is close to the entrepreneur itself from the spatial level, then the social entrepreneurs will psychologically characterize the relevant cognitive information with a low degree of abstraction. It is based on the perception of spatial distance by social entrepreneurs that affects the final cognition, which in turn leads to different grounds for social entrepreneurs to judge and make decisions. Combined with the theory of construal Level, this paper argues that social entrepreneurs have higher identification of social entrepreneurial opportunities with higher degree of abstraction, while psychological representations with lower abstraction have a lower identification of social entrepreneurial opportunities. Based on this, the following assumption is made:

H2: Spatial distance has a significant positive impact on the identification of social entrepreneurial opportunities.

\subsection{Relationship between social distance and social entrepreneurship opportunity identification}

Social distance, as the cognitive dimension of the individual, affects the individual's psychology and behavior based on the perception of the relationship between people. According to the theory of construal Level, if the individual perceives the social distance, initiate a high level of interpretation, pay attention to the nature of the event or behavior and the core content; if the individual perceives the social distance, initiate a low level of interpretation, pay attention to the specific details and details of the event or behavior Content. It is precisely because of the individual's perception of the distance between the person and the person (self-others, friends, strangers, etc.), which affects the focus of individual judgment and decision-making. The study points out that in the decision-making of self-others, individuals consider many factors in the decision-making bias of self-related, pay attention to the details and specific content of decision-making matters, and consider the decision-related related when the individual acts as a suggestor to help others make decisions. A major content, often overlooking other details or irrelevant factors (Kray \& Gonzalez, 1999). In this regard, Trope, Liberman, and Wakslak (2007) further point out that if others are less similar to themselves, the social relationship between them becomes alienated. When individuals make decisions for themselves, the perceived psychological distance is zero, the information about decision-making matters is rich, the low-level construal Level is initiated, and the specific and detailed content is too much attention; when the individual makes decisions on others, due to perception The distance to the society is far, the information on decision-making matters is very small, and the individual is encouraged to initiate a high-level construal Level. The highly abstracted approach focuses on the core content of the decision-making itself. In addition, Lu et al. (2013) pointed out that individuals are more focused on the feasibility of behavior when making decisions for themselves, while focusing on the desirability of behavior when making decisions for others. The above analysis shows that the subjective level of the individual faces the perception and decision-making of the perceived impact of social distance. According to this, in combination with the identification of social entrepreneurial opportunities, when social entrepreneurs are concerned with their own decision-making matters, they are often surrounded by a large amount of complex information, which makes it impossible for entrepreneurs to effectively grasp the main information related to social entrepreneurial opportunities, leading to judgment and On the contrary, if social entrepreneurs can look at their own decisions when they are making decisions, they are more likely to focus on the core content related to social entrepreneurship opportunities, which will promote the further identification of entrepreneurial opportunities. In this regard, the paper proposes the following assumption:

H3: Social distance has a significant positive impact on the identification of social entrepreneurship opportunities.

\subsection{Relationship between probability distance and social entrepreneurship opportunity identification}

Probability distance is the individual's cognitive dimension, which influences judgment and decision based on the likelihood of an individual's occurrence of an event or behavior. At present, the academic community has less discussion on probability distance, but according to the psychological distance, the individual has a high level of construal Level, focusing on the event or behavioral essence and core content, and the probability distance is close. 
An event or behavior that initiates a low level of interpretation, focusing on event or behavioral details and contextualized content (Trope, Liberman \& Wakslak, 2007). The reason is mainly because the psychological distance of the event or behavior with small possibility of individual perception is far away, the information is less, the cognition is very abstract, and the individual decision-making is only concerned with the core and essential information related to decision-making; Events or behaviors with high probability of occurrence, the psychological distance of individual perception is close, the information is rich, and the degree of cognitive abstraction is low, which makes the individual decision-making too concerned about details and background content. It is precisely because of the individual's perception of the size of the possibility that it ultimately affects the psychological representation and behavior. Some scholars have studied this, the results show that individuals highlight the characteristics related to goals for events or behaviors with low probability, and do better for events or behaviors with high probability (Todorov et al., 2007). In combination with the identification of social entrepreneurial opportunities, the perception of the likelihood of social entrepreneurs' success in social entrepreneurship affects their psychological representation and subsequent decision-making behavior. Specifically, if social entrepreneurs perceive that social entrepreneurship is less likely to succeed, it will promote them to highly abstract the acquired information and extract essential and core information. In addition, they take entrepreneurial activities seriously, which will promote the identification of social entrepreneurial opportunities. If social entrepreneurs perceive the possibility of successful social entrepreneurship, they will enable them to face rich information in a low degree of abstraction. Instead, they will not be able to find important information related to social entrepreneurial opportunities in the flood of information. It is not conducive to subsequent identification behavior. In this regard, the paper proposes the following assumptions:

H4: Probability distance has a significant positive impact on social entrepreneurship opportunity identification.

Based on the above analysis, this paper constructs a model of the psychological distance to social entrepreneurship opportunity identification based on the four distance dimensions of time, space, society and probability (as shown in Figure 1).

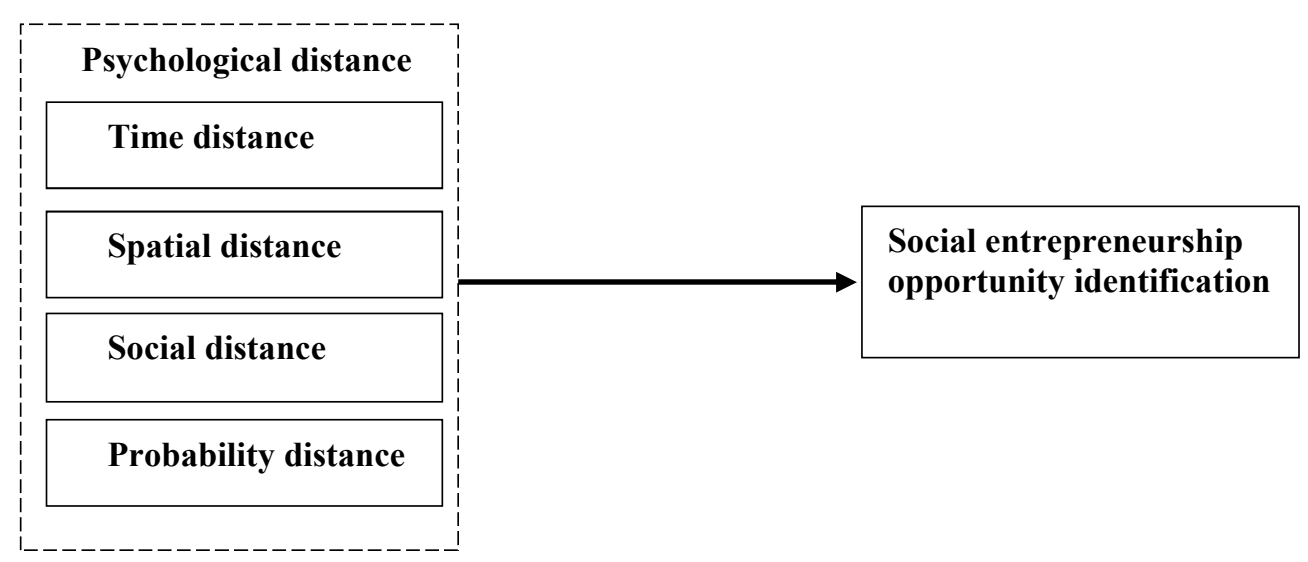

Figure 1 Social entrepreneurship opportunity identification

\section{Research conclusions and prospects}

Based on the theory of construal Level, this paper expounds the related theories of psychological distance and social entrepreneurship opportunity identification, and analyzes the relationship between time distance, spatial distance, social distance, probability distance and social entrepreneurship opportunity identification. The corresponding propositions are put forward to construct a psychological distance to identify the impact model of social entrepreneurship opportunities. For social entrepreneurs, the judgment of social entrepreneurial opportunities is based on information understanding, but because of the different psychological distances of entrepreneurial information perception, especially the timing, spatial location and decision-making relationship of social entrepreneurial opportunities The perceived difference between the four main factors and the possibility causes them to form a social cognition of different levels of abstraction of social entrepreneurial information, which ultimately affects the judgment of social entrepreneurial opportunities.

It is undeniable that the research in this paper introduces cognitive psychology into the field of social entrepreneurship opportunity identification, which has important theoretical significance for expanding the application of cognitive psychology, especially the development of social entrepreneurship opportunity identification theory. However, the research in this paper is also insufficient. First, this paper makes theoretical analysis and hypothesis based on the theoretical level that the psychological distance may affect the identification of social entrepreneurial opportunities, but the final research results need to be further verified by empirical 
analysis. Therefore, future research is best to conduct empirical analysis based on certain sample data, thus deepening the relationship between psychological distance and social entrepreneurship opportunity identification. Second, this paper makes assumptions from the relationship between psychological distance and social entrepreneurship opportunity identification, but it cannot be ruled out that psychological distance needs to be applied to other factors to ultimately influence social entrepreneurship opportunity identification. Therefore, future research can introduce mediator variables and construct a complete social entrepreneurship opportunity identification model.

\section{References}

Ardichvili, A., Cardozo, R., \& Ray, S. (2003). A theory of entrepreneurial opportunity identification and development. Journal of Business venturing, 18(1), 105-123.

Austin, J., Stevenson, H., \& Wei-Skillern, J. (2012). Social and commercial entrepreneurship: same, different, or both?. Revista de Administração, 47(3), 370-384.

Baron, R. A. (2006). Opportunity recognition as pattern recognition: How entrepreneurs "connect the dots" to identify new business opportunities. Academy of management perspectives, 20(1), 104-119.

Choi, N., \& Majumdar, S. (2014). Social entrepreneurship as an essentially contested concept: Opening a new avenue for systematic future research. Journal of business venturing, 29(3), 363-376.

Fujita, K., Henderson, M. D., Eng, J., Trope, Y., \& Liberman, N. (2006). Spatial distance and mental construal of social events. Psychological Science, 17(4), 278-282.

Chen, H. S., Mitchell, R. K., Brigham, K. H., Howell, R., \& Steinbauer, R. (2018). Perceived psychological distance, construal processes, and abstractness of entrepreneurial action. Journal of Business Venturing, 33(3), 296-314.

Dacin, M. T., Dacin, P. A., \& Tracey, P. (2011). Social entrepreneurship: A critique and future directions. Organization science, 22(5), 1203-1213.

Guclu, A., Dees, J. G., \& Anderson, B. B. (2002). The process of social entrepreneurship: Creating opportunities worthy of serious pursuit. Center for the advancement of Social Entrepreneurship, 1, 1-15.

Kray, L., \& Gonzalez, R. (1999). Differential weighting in choice versus advice: I'll do this, you do that. Journal of Behavioral Decision Making, 12(3), 207-218.

McMullen, J. S., \& Shepherd, D. A. (2006). Entrepreneurial action and the role of uncertainty in the theory of the entrepreneur. Academy of Management review, 31(1), 132-152.

Liberman, N., \& Trope, Y. (1998). The role of feasibility and desirability considerations in near and distant future decisions: A test of temporal construal theory. Journal of personality and social psychology, 75(1), 5.

Liberman, N., Sagristano, M. D., \& Trope, Y. (2002). The effect of temporal distance on level of mental construal. Journal of experimental social psychology, 38(6), 523-534.

Lu, J., Xie, X., \& Xu, J. (2013). Desirability or feasibility: Self-other decision-making differences. Personality and Social Psychology Bulletin, 39(2), 144-155.

Shaver, K. G., \& Scott, L. R. (1992). Person, process, choice: The psychology of new venture creation. Entrepreneurship theory and practice, 16(2), 23-46.

Shane, S., \& Venkataraman, S. (2000). The promise of entrepreneurship as a field of research. Academy of management review, 25(1), 217-226.

Smith, P. K., \& Trope, Y. (2006). You focus on the forest when you're in charge of the trees: power priming and abstract information processing. Journal of personality and social psychology, 90(4), 578.

Stevens, R., Moray, N., \& Bruneel, J. (2015). The social and economic mission of social enterprises: Dimensions, measurement, validation, and relation. Entrepreneurship Theory and Practice, 39(5), 1051-1082.

Trope, Y., \& Liberman, N. (2003). Temporal construal. Psychological review, 110(3), 403.

Todorov, A., Goren, A., \& Trope, Y. (2007). Probability as a psychological distance: Construal and preferences. Journal of Experimental Social Psychology, 43(3), 473-482.Trope Y, Trope, Y., Liberman, N., \& Wakslak, C. (2007). Construal levels and psychological distance: Effects on representation, prediction, evaluation, and behavior. Journal of consumer psychology, 17(2), 83-95.

Trope, Y., \& Liberman, N. (2010). Construal-level theory of psychological distance. Psychological review, 117(2), 440.

Weerawardena, J., \& Mort, G. S. (2006). Investigating social entrepreneurship: A multidimensional model. Journal of world business, 41(1), 21-35.

Wakslak, C. J., Trope, Y., Liberman, N., \& Alony, R. (2006). Seeing the forest when entry is unlikely: probability and the mental representation of events. Journal of Experimental Psychology: General, 135(4), 641.

Yitshaki, R., \& Kropp, F. (2015). Entrepreneurial Passions and Identities among High-Tech and Social Entrepreneurs. In Academy of Management Proceedings (Vol. 2015, No. 1, p. 17305). Briarcliff Manor, NY 10510: Academy of Management. 
Hao Zhang(1992-),male, Dian jiang, Chong Qing, master graduate student of the School of Public Affairs, University of Science and Technology of China, majoring in Social entrepreneurship and regional development. Xiaobao Peng(1981-), male, Huang Shi, Hubei Province, Associate professor, PhD, master supervisor, school of public affairs, university of science and technology of China, social entrepreneurship and innovation management. 